\title{
Vascular Access Graft Failure
}

National Cancer Institute

\section{Source}

National Cancer Institute. Vascular Access Graft Failure. NCI Thesaurus. Code C84459.

Failure to achieve vascular access due to damage of the graft that was created for this purpose. 